\title{
Editorial: Preventing Developmental Brain Injury-From Animal Models to Clinical Trials
}

\author{
Masahiro Tsuji ${ }^{1}$, Stéphane V. Sizonenko ${ }^{2 \star}$ and Olivier Baud ${ }^{3,4}$ \\ ${ }^{1}$ Department of Food and Nutrition, Kyoto Women's University, Kyoto, Japan, ${ }^{2}$ Division of Development and Growth, \\ Department of Pediatrics, Gynecology and Obstetrics, School of Medicine, University of Geneva, Geneva, Switzerland, \\ ${ }^{3}$ Division of Neonatology, Department of Pediatrics Gynecology and Obstetrics, School of Medicine, University of Geneva, \\ Geneva, Switzerland, ${ }^{4}$ Robert Debré Hospital, INSERM U1141, Paris-Diderot University, Paris, France
}

Keywords: neonatal encephalopathy, brain injury, prematurity and low birth weight, animal model, clinical study

Editorial on the Research Topic

Preventing Developmental Brain Injury-From Animal Models to Clinical Trials

OPEN ACCESS

Edited by:

Jo Madeleine Wilmshurst, University of Cape Town, South Africa

Reviewed by:

Mary Ann Rutherford,

King's College London,

United Kingdom

Richard Joseph Burman,

University of Oxford, United Kingdom

*Correspondence:

Stéphane V. Sizonenko

Stephane.Sizonenko@unige.ch

Specialty section:

This article was submitted to

Pediatric Neurology,

a section of the journal

Frontiers in Neurology

Received: 20 April 2019

Accepted: 03 July 2019

Published: 19 July 2019

Citation:

Tsuji M, Sizonenko SV and Baud O (2019) Editorial: Preventing

Developmental Brain Injury - From Animal Models to Clinical Trials.

Front. Neurol. 10:775

doi: 10.3389/fneur.2019.00775
A variety of brain injuries originating from fetal, perinatal, and neonatal periods may cause mortality, and many of the survivors of those injuries suffer from life-long morbidity. It is our task as researchers to prevent and reduce such brain injuries in infants. This is why we Topic Editors chose the theme "Preventing developmental brain injury_from animal models to clinical trials."

Among those developing brain injuries, neonatal encephalopathy in full-term infants has been the most crucial issue for decades (1). Neonatal encephalopathy refers to newborns with symptoms of acute cerebral dysfunction such as depressed consciousness, abnormal muscle tone, respiratory distress, feeding difficulties, and seizures $(2,3)$. Hypoxic-ischemic injury is the most common (up to $85 \%$ of cases), and ischemic/hemorrhagic stroke is the second most common, etiology and pathophysiology of neonatal encephalopathy (3). Approximately $3 \%$ of babies born in the world die by 4 weeks of age, and asphyxia, i.e., neonatal encephalopathy accounts for $23 \%$ of neonatal mortality (4); hence, the mortality rate due to neonatal encephalopathy is estimated to be 70/1,000 livebirths. Almost all (99\%) neonatal mortality occurs in resource-limited countries (4). The incidence of neonatal encephalopathy in term newborns has been declining in resource-rich countries, and is currently $1 / 1,000$ livebirths or less $(5,6)$. Nevertheless, nearly half of infants with neonatal encephalopathy in resource-rich countries die or develop permanent neurological disabilities, such as cerebral palsy, intellectual disability, and epilepsy (7). Therefore, the burden of neonatal encephalopathy remains high for patients, caregivers, and society.

Currently, the most common brain injuries caused during fetal, perinatal, and neonatal periods are those associated with prematurity, i.e., fetal growth restriction, preterm birth, and low birth weight (8). Approximately 15 million newborns were estimated to be born preterm $(<37$ weeks of gestation) in 2010, which accounted for $11 \%$ of all livebirths worldwide, ranging from $5 \%$ in some European countries to $18 \%$ in some African countries (9). The preterm birth rate has been increasing over the past two decades (9). Similarly, the rate of low birth weight (birth weight is $<2,500 \mathrm{~g}$ ) has been increasing: $7-9 \%$ of all live births in resource-rich countries $(10,11)$ and $11-12 \%$ in resource-limited countries (12). Intrauterine hypoperfusion and inflammation are the two leading causes of brain injuries associated with prematurity (13-16). Although most infants do not present obvious neurological symptoms during the neonatal period, they may develop cerebral palsy and neurodevelopmental disorders such as attention-deficit/hyperactive disorders and autistic spectrum disorders during childhood $(17,18)$. Survivors of very low birth weight $(<1,500 \mathrm{~g})$ may present cerebral palsy in $5-10 \%$ of the individuals and cognitive/behavioral/attentional deficits 
in $\sim 50 \%$ of these individuals $(19,20)$. The main focus of outcome studies in neonatal care has been the extremely low-birth-weight $(<1,000 \mathrm{~g})$ infants and extremely preterm infants [born before 28 weeks of gestation (9)]. Recent studies, however, have shown that even infants born with mild prematurity (birth weight is 1,500$<2,500$ g; gestational age is $32-<37$ weeks) have significantly higher risks of developing numerous neurological, psychological, and general health problems later in life (21). This phenomenon is now widely known as $\mathrm{DOHaD}$ (developmental origin of health and diseases) (22). While many preclinical studies have been conducted in neonatal encephalopathy, a limited number of preclinical studies have been conducted regarding brain injuries associated with prematurity.

Neonatal encephalopathy and brain injury associated with prematurity seem to be contrasting problems, as the former is a medical emergency during the neonatal period, while the latter is a gradually emerging problem in childhood. While it is important to shed light on rare brain injuries, neonatal encephalopathy in term infants and brain injuries associated with prematurity are the most prominent issues that researchers and funding sources need to address considering their impact on patients and society.

This Research Topic collects 29 articles: 20 animal studies (including 1 in vitro study), 3 clinical studies, 1 combined study with clinical and animal studies, and 5 reviews. Of the 21 animal studies, the majority used rodents, and 3 studies used large animals, i.e., piglets or lambs. Hypoxic-ischemic injury was the most frequently used model (11 articles) in this Research Topic collection. Other models included intrauterine ischemia/inflammation ( 3 articles) and irradiation ( 2 articles). As the theme of this Research Topic was "preventing developing brain injury," many of the animal studies explored the effects of novel therapies. Five studies examined the effects of cellbased therapies, 2 studies examined erythropoietin, and others examined melatonin, inhaled carbon dioxide therapy, and protective ventilation strategies. Some studies examined the effects of certain genomic modifications as possible targets of novel therapies. Clinical studies investigated EEG and blood pressure, IL-10 gene polymorphism, and cerebral lactate in infants with brain damage. Despite the Topic Editors' expectations, there was no manuscript submission of an

\section{REFERENCES}

1. Aicardi J. Neurological diseases in the perinatal period. In: Aicardi J, editor. Diseases of the Nervous System in Childhood, 2nd Ed. London: Mac Keith Press (1998) p. 32-66.

2. Johnston MV, Fatemi A, Wilson MA, Northington F. Treatment advances in neonatal neuroprotection and neurointensive care. Lancet Neurol. (2011) 10:372-82. doi: 10.1016/S1474-4422(11)70016-3

3. Volpe JJ. Neonatal encephalopathy: an inadequate term for hypoxic-ischemic encephalopathy. Ann Neurol. (2012) 72:156-66. doi: 10.1002/ana.23647

4. Lawn JE, Cousens S, Zupan J, Lancet Neonatal Survival Steering Team. 4 million neonatal deaths: when? where? why? Lancet. (2005) 365:891-900. doi: 10.1016/S0140-6736(05)71048-5

5. Becher JC, Stenson BJ, Lyon AJ. Is intrapartum asphyxia preventable? BJOG. (2007) 114:1442-4. doi: 10.1111/j.1471-0528.2007.01487.x interventional clinical trial, which may suggest a scarcity of clinical trials and difficulty in conducting clinical trials of novel therapies in sick infants. The review articles summarized the effects of therapies, such as oxytocin, magnesium, and nitric oxide synthase inhibition.

With respect to the demographics of this Research Topic collection, the corresponding author's laboratories are located in a variety of countries: Japan (6 articles), the United States (5 articles), France (4 articles), the United Kingdom (3 articles), Sweden (3 articles), the Netherlands (2 articles), Switzerland (1 article), Germany (1 article), China (1 article), South Korea (1 article), Canada (1 article), and Australia (1 article). Thirteen articles represent international collaborative studies.

The Topic Editors are pleased to have a wide variety of 29 articles from many countries around the world. None of the articles in this collection, however, are from the resource-limited world. It is important to encourage research in this area in resource-limited countries where developmental brain injuries are expected to be most prevalent. We hope that research on neonatal brain injuries will become even more active and will contribute to better preventions and treatments for these injuries in the near future.

\section{AUTHOR CONTRIBUTIONS}

MT wrote the draft. SS and OB critically reviewed the manuscript.

\section{FUNDING}

MT was supported by JSPS KAKENHI Grant Number 17K10200, JSPS Bilateral Open Partnership Joint Research Projects, and the Joint Research Project of the Institute of Medical Science, the University of Tokyo (2017-1017). SS was supported by Swiss Excellence Scholarship for Foreign Scholars, by the Swiss National Fund No. 33CM30-124101/140334 and the Fondation pour Recherches Médicales, Geneva.

\section{ACKNOWLEDGMENTS}

We thank all the reviewers who provided useful suggestions to improve the manuscript.

6. Hayakawa M, Ito Y, Saito S, Mitsuda N, Hosono S, Yoda H, et al. Incidence and prediction of outcome in hypoxic-ischemic encephalopathy in Japan. Pediatr Int. (2014) 56:215-21. doi: 10.1111/ped.12233

7. Shankaran S, Pappas A, McDonald SA, Vohr BR, Hintz SR, Yolton K, et al. Childhood outcomes after hypothermia for neonatal encephalopathy. $\mathrm{N} \mathrm{Engl}$ J Med. (2012) 366:2085-92. doi: 10.1056/NEJMoa1112066

8. Blencowe H, Lee AC, Cousens S, Bahalim A, Narwal R, Zhong N, et al. Preterm birth-associated neurodevelopmental impairment estimates at regional and global levels for 2010. Pediatr Res. (2013) 74(Suppl. 1):17-34. doi: 10.1038/pr.2013.204

9. Blencowe H, Cousens S, Oestergaard MZ, Chou D, Moller AB, Narwal $\mathrm{R}$, et al. National, regional, and worldwide estimates of preterm birth rates in the year 2010 with time trends since 1990 for selected countries: a systematic analysis and implications. Lancet. (2012) 379:2162-72. doi: 10.1016/S0140-6736(12)60820-4 
10. Morisaki N, Esplin MS, Varner MW, Henry E, Oken E. Declines in birth weight and fetal growth independent of gestational length. Obstet Gynecol. (2013) 121:51-8. doi: 10.1097/AOG.0b013e3182 $78 \mathrm{~d} 014$

11. Vital Statistics/Vital Statistics of Japan Final data Natality. Live Births Distributed According to Birth Weight and Mean Birth Weight, by Sex, Period of Gestation and Plurality of Birth: Japan 2015. Ministry of Health Labour and Welfare (2016). Available online at: https://www.e-stat.go. jp/en/stat- search/files?page $=1$ \&layout $=$ datalist\&toukei $=00450011 \&$ tstat $=$ $000001028897 \&$ cycle $=7 \&$ year $=20150 \&$ month $=0 \&$ tclass $1=000001053058 \&$ tclass $2=000001053061 \&$ tclass $3=000001053064 \&$ stat_infid $=000031448902$

12. Dhaded SM, Somannavar SS, Vernekar SS, Goudar M, Mwenche R, Derman JL, et al. Neonatal mortality and coverage of essential newborn interventions 2010 - 2013: a prospective, population-based study from low-middle income countries. Reprod Health. (2015) 12(Suppl. 2):S6. doi: 10.1186/1742-4755-12-S2-S6

13. Kaukola T, Herva R, Perhomaa M, Paakko E, Kingsmore S, Vainionpaa L, et al. Population cohort associating chorioamnionitis, cord inflammatory cytokines and neurologic outcome in very preterm, extremely low birth weight infants. Pediatr Res. (2006) 59:478-83. doi: 10.1203/01.pdr.0000182596.6 6175.ee

14. Redline RW, Minich N, Taylor HG, Hack M. Placental lesions as predictors of cerebral palsy and abnormal neurocognitive function at school age in extremely low birth weight infants (<1 kg). Pediatr Dev Pathol. (2007) 10:28292. doi: 10.2350/06-12-0203.1

15. Trivedi S, Joachim M, McElrath T, Kliman HJ, Allred EN, Fichorova R, et al. Fetal-placental inflammation, but not adrenal activation, is associated with extreme preterm delivery. Am J Obstet Gynecol. (2012) 206:e231-8. doi: 10.1016/j.ajog.2011.12.004

16. Kovo M, Schreiber L, Bar J. Placental vascular pathology as a mechanism of disease in pregnancy complications. Thromb Res. (2013) 131(Suppl. 1):S1821. doi: 10.1016/S0049-3848(13)70013-6
17. Anderson P, Doyle LW. Neurobehavioral outcomes of school-age children born extremely low birth weight or very preterm in the 1990s. JAMA. (2003) 289:3264-72. doi: 10.1001/jama.289.24.3264

18. Levine TA, Grunau RE, McAuliffe FM, Pinnamaneni R, Foran A, Alderdice FA. Early childhood neurodevelopment after intrauterine growth restriction: a systematic review. Pediatrics. (2015) 135:126-41. doi: 10.1542/peds.2014-1143

19. Hack M, Taylor HG, Drotar D, Schluchter M, Cartar L, Wilson-Costello D, et al. Poor predictive validity of the Bayley Scales of Infant Development for cognitive function of extremely low birth weight children at school age. Pediatrics. (2005) 116:333-41. doi: 10.1542/peds.2005-0173

20. Wilson-Costello D, Friedman H, Minich N, Siner B, Taylor G, Schluchter $\mathrm{M}$, et al. Improved neurodevelopmental outcomes for extremely low birth weight infants in 2000-2002. Pediatrics. (2007) 119:37-45. doi: 10.1542/peds.2006-1416

21. Sucksdorff M, Lehtonen L, Chudal R, Suominen A, Joelsson P, Gissler M, et al. Preterm birth and poor fetal growth. Pediatrics. (2015) 136:e599-608. doi: 10.1542/peds.2015-1043

22. Hanson MA, Gluckman PD. Early developmental conditioning of later health and disease: physiology or pathophysiology? Physiol Rev. (2014) 94:1027-76. doi: 10.1152/physrev.00029.2013

Conflict of Interest Statement: The authors declare that the research was conducted in the absence of any commercial or financial relationships that could be construed as a potential conflict of interest.

Copyright (c) 2019 Tsuji, Sizonenko and Baud. This is an open-access article distributed under the terms of the Creative Commons Attribution License (CC BY). The use, distribution or reproduction in other forums is permitted, provided the original author(s) and the copyright owner(s) are credited and that the original publication in this journal is cited, in accordance with accepted academic practice. No use, distribution or reproduction is permitted which does not comply with these terms. 